7. Reprod. Fert. (1967) 14, 387-392

\title{
TRANSAMINASE IN HUMAN SEMEN
}

\author{
R. ELIASSON \\ Department of Physiology, Faculty of Medicine, \\ Karolinska Institutet, Stockholm
}

(Received 16th August 1966)

\begin{abstract}
Summary. Determinations of aspartate and alanine aminotransferase activity in human semen were carried out by the spectrophotometric and colorimetric methods. It was found that the occurrence of interfering substances in semen makes the spectrophotometric method unsuitable without prior partial purification of the enzyme. The mean activity determined colorimetrically in 417 samples of human semen was 320 Sigma-Frankel units $/ \mathrm{ml}$ (s.E.M. \pm 8 , range 10 to 1070) for aspartate aminotransferase and 30 units $/ \mathrm{ml}$ (s.E.M. \pm 3 , range 0 to $97, n=40$ ) for alanine aminotransferase. As regards aspartate aminotransferase, the activity of this enzyme was highest at $+60^{\circ} \mathrm{C}$. Pyridoxal phosphate increased the activity, particularly if added to semen samples with initially low activity. Gel electrophoresis of seminal plasma showed one band migrating towards the anode. However, in homogenized spermatozoa the bulk of enzyme migrated towards the cathode and only a weak band could be demonstrated on the side of the anode.
\end{abstract}

\section{INTRODUCTION}

The occurrence of aspartate aminotransferase* and alanine aminotransferase in semen from man and certain mammals has been demonstrated by Povoa \& Villela (1960), Flipse (1960), Gregoire, Rakoff \& Ward (1961), Searcy, Craig \& Bergquist (1962), Pumpianski \& Sharon (1965), Joel \& Herzberg (1965) and others. The aspartate aminotransferase activity in human semen was usually 10 to 20 times that in normal blood plasma. There appeared to be a correlation between the enzyme activity and the sperm density both in human and bull semen. It has been suggested that part of the aspartate aminotransferase activity could be due to a leakage of enzymes from the spermatozoa (Flipse, 1960).

In the present study, the occurrence and some properties of aspartate and alanine aminotransferases in human semen have been explored.

\section{MATERIALS AND METHODS}

Semen samples were obtained from patients attending infertility clinics and from volunteers. In most cases, part of the semen sample was transferred to a

* Aspartate aminotransferase = glutamic oxaloacetic transaminase, EC 2.6.1.1.; alanine aminotransferase $=$ glutamic pyruvic transaminase, EG 2.6.1.2.; in accordance with Enzyme Nomenclature: Recommendations 1964 of the International Union of Biochemistry. 
small glass tube and kept at $-20^{\circ} \mathrm{C}$ until analysed. The analyses were usually performed within 2 weeks. Control experiments revealed that the storage used did not influence the assays. Before the analyses, the semen was thawed at room temperature and centrifuged to remove the spermatozoa.

Determinations of aspartate and alanine aminotransferases were performed by two methods: the colorimetric method of Reitman \& Frankel (1957) and the spectrophotometric method of Karmen (1955) as modified by Ordell (1956). In the first method, Sigma Chemical Co. reagents were used and the activity expressed in Sigma-Frankel units (Technical Bulletin No. 505, Sigma Chemical Co.). In determining the aspartate aminotransferase, the samples were usually diluted five times with normal saline, while in determining the alanine aminotransferase, the semen was used undiluted. The colour was read at $505 \mathrm{~m} \mu$ against water in a Beckman B or Beckman DB spectrophotometer. Seminal plasma contains pyruvic acid and possibly other substances which yield hydrazones. Therefore, the extinction after $30 \mathrm{~min}$ (alanine aminotransferase) or $60 \mathrm{~min}$ (aspartate aminotransferase) of incubation at $37^{\circ} \mathrm{C}$ was corrected by subtracting the extinction obtained in the control samples (no incubation). The extinction of the control samples usually corresponded to 20 to 40 ' units' $/ \mathrm{ml}$ (range 10 to 90 'units').

In the spectrophotometric method, the oxidation of NADH was followed by measuring the decrease in light absorption at $340 \mathrm{~m} \mu$; the reagents were obtained from Messrs KABI (Sweden).

Partial purification of the enzyme was performed by gel filtration on Sephadex G-25 or G-100 ( $2 \times 50 \mathrm{~cm}$ columns) according to Flodin (1962), using potassium-sodium-phosphate buffer, $0.1 \mathrm{~m}$ and $\mathrm{pH} 7.4$ for elution. The fractions ( $4 \mathrm{ml}$ each) with highest activity were pooled and concentrated by ultrafiltration through a collodion membrane.

The occurrence of isoenzymes of aspartate aminotransferase was studied separately in seminal plasma and disintegrated spermatozoa by starch gel electrophoresis (Decker \& Rau, 1963). Prior to use, the seminal plasma was centrifuged at $30,000 \mathrm{~g}$ for $30 \mathrm{~min}$ and concentrated about three times by ultrafiltration. The spermatozoa were washed three times with isotonic saline, disintegrated in a Potter-Elvehjem homogenizer, and the extract concentrated by ultrafiltration.

The effect of pyridoxal-5-phosphate (vitamin $\mathrm{B}_{6}$ ) (Sigma Chemical Co.) was studied by adding this substance dissolved in $0.9 \%(\mathrm{w} / \mathrm{v})$ saline to the semen samples. Equal volumes of saline were added to the control samples.

\section{RESULTS}

Assay with the colorimetric method

For both aminotransferases, there was a linear relationship between the activity (Reitman-Frankel units) and the degree of dilution (1:1 to $1: 10)$ or the time of incubation ( 0 to $60 \mathrm{~min}$ ) when native seminal plasma was used. The accuracy of the method in determining aspartate aminotransferase had a S.E.M. $\pm 5 \cdot 2(n=10)$ and for alanine aminotransferase $\pm 1 \cdot 9(n=10)$.

The mean aspartate aminotransferase activity was 321 units/ml (s.E.M. \pm 8 , 
range 10 to $1070, n=417)$. The percentage distribution of the activity is presented in Table 1. The mean alanine aminotransferase was 30 units (s.E.M. $3 \cdot 1$, range 0 to $97, n=40$ ).

Changes in the enzyme activity (colorimetric method) with time in whole semen and seminal plasma were studied in five samples obtained within $15 \mathrm{~min}$ after ejaculation and divided in two equal parts-one being centrifuged to remove the sperm cells. The aspartate aminotransferase activity of the seminal plasma was slightly lower (about 80\%) than that of the total semen. No such difference was noted for the alanine aminotransferase activity. There was no change in either of the aminotransferase activities in the semen or seminal plasma within the time of observation $(4 \mathrm{hr})$. Sperm density in the semen samples varied from 20 to 115 millions $/ \mathrm{ml}$.

TABLE 1

FREQUENCY DISTRIBUTION OF ASPARTATE AMINOTRANSFERASE (= GLUTAMIC OXALOACETIC TRANSAMINASE, GOT) IN 417 SAMPLES OF HUMAN SEMEN

\begin{tabular}{c|c}
\hline $\begin{array}{c}\text { GOT } \\
(\text { units } / \mathrm{ml})\end{array}$ & $\begin{array}{c}\text { Percentage } \\
\text { of samples }\end{array}$ \\
\hline $0-50$ & $0 \cdot 7$ \\
$51-100$ & $6 \cdot 5$ \\
$101-150$ & $10 \cdot 3$ \\
$151-200$ & $16 \cdot 1$ \\
$201-250$ & $13 \cdot 4$ \\
$251-300$ & $11 \cdot 0$ \\
\hline
\end{tabular}

\begin{tabular}{c|c}
\hline $\begin{array}{c}G O T \\
(\text { units } / m l)\end{array}$ & $\begin{array}{c}\text { Percentage } \\
\text { of samples }\end{array}$ \\
\hline $301-350$ & $9 \cdot 1$ \\
$351-400$ & $9 \cdot 4$ \\
$401-450$ & $6 \cdot 3$ \\
$451-500$ & $5 \cdot 5$ \\
$501-550$ & $3 \cdot 4$ \\
$551-600$ & $2 \cdot 6$ \\
\hline
\end{tabular}

\begin{tabular}{c|c}
\hline $\begin{array}{c}\text { GOT } \\
\text { (units } / \mathrm{ml})\end{array}$ & $\begin{array}{c}\text { Percentage } \\
\text { of samples }\end{array}$ \\
\hline $601-650$ & 1.7 \\
$651-700$ & $0 \cdot 7$ \\
$701-750$ & 0.7 \\
$751-800$ & $0 \cdot 7$ \\
$>800$ & 1.9 \\
$\bar{x}=320$ & $\Sigma 100$ \\
\hline
\end{tabular}

* Reitman-Frankel units.

Assay with the spectrophotometric method

The spectrophotometric method includes a period of pre-incubation before $\alpha$-ketoglutaric acid is added to the mixture. During this period, there is a steady decrease in absorption at $340 \mathrm{~m} \mu$ due to reduction of oxo-acids present by the added and endogenous dehydrogenase. Human semen contains, however, much more oxo-acids than blood serum. In some samples the amount was so high that reduced coenzyme had to be added several times before a steady state was obtained. If alanine was omitted from the reaction mixture, only a minor part of the DPNH was oxidized.

Many samples showed a good correlation between the aspartate aminotransferase activity and the degree of dilution of the semen. For some samples, however, the occurrence of interfering factors obviously resulted in lower values when seminal plasma diluted 1:1 or 1:2 was compared to higher dilutions $(1: 5$ and $1: 10)$.

The same type of interference occurred in most samples in determining the alanine aminotransferase activity in native seminal plasma with varying degrees of dilution $(1: 1$ to $1: 10)$.

The interfering substances could be partially removed by gel filtration on Sephadex G-25 or ultrafiltration. After such a purification, there was a good correlation between the degree of dilution and the aspartate and alanine aminotransferase activities. 
Assay of fifty-two samples (native but diluted 1:5) gave a mean aspartate aminotransferase activity of $421 \mathrm{Karmen}-$ Ordell units/ml (s.E.M. \pm 39 , range 75 to 1590 ).

The aspartate aminotransferase activity in twenty randomly selected samples was determined with both the colorimetric $(y)$ and spectrophotometric $(x)$ methods. The coefficient of correlation was $r=0 \cdot 9$, and the activity in SigmaFrankel units was on the average $60 \%$ of that expressed in Karmen-Ordell units (least square regression line $y=4 \cdot 7+0.59 x$ ). In some specimens, however, there was no such correlation between the results of the two methods.

TABLE 2

TEMPERATURE STABILITY OF ASPARTATE AMINOTRANSFERASE FROM HUMAN SEMINAL PLASMA

\begin{tabular}{c|c}
\hline Pre-incubation temperature $\left({ }^{\circ} \mathrm{C}\right)$ & Percentage activity at $37^{\circ} \mathrm{C}$ \\
\hline 37 & 100 \\
50 & 100 \\
60 & 100 \\
65 & 35 \\
70 & 5 \\
75 & $<5$ \\
\hline
\end{tabular}

After pre-incubation of the seminal plasma at various temperatures for $20 \mathrm{~min}$, the activity was determined at $37^{\circ} \mathrm{C}$.

TABLE 3

INGREASE OF ASPARTATE AMINOTRANSFERASE ACTIVITY AS PERCENTAGE OF CONTROL AFTER ADDITION OF VITAMIN B 6 (PYRIDOXAL PHOSPHATE) TO HUMAN SEMINAL PLASMA

\begin{tabular}{c|c|cc}
\hline \multirow{3}{*}{$\begin{array}{c}\text { Sample } \\
\text { No. }\end{array}$} & $\begin{array}{c}\text { Enzyme activity } \\
\text { in controls }\end{array}$ & \multicolumn{2}{|c}{$\begin{array}{c}\text { Percentage increase* in activity } \\
\text { after addition of vitamin } B_{6}\end{array}$} \\
\cline { 2 - 3 } & & $50 \mu \mathrm{g} / \mathrm{ml}$ & $100 \mu \mathrm{g} / \mathrm{ml}$ \\
\hline 1 & 70 & & 290 \\
2 & 145 & 178 & 275 \\
3 & 160 & 197 \\
4 & 265 & 117 & 160 \\
5 & 290 & 106 & 145 \\
6 & 525 & & 140 \\
7 & 680 & & 120 \\
8 & 800 & & \\
\hline
\end{tabular}

* e.g. the enzyme activity of sample No. 3 after addition of $50 \mu \mathrm{g} / \mathrm{ml}$ vitamin $B_{6}$ is 285 units $(160 \times 178 / 100)$.

\section{Thermostability}

Incubation of semen samples at various temperatures between $37^{\circ} \mathrm{C}$ and $75^{\circ} \mathrm{C}$ gave the highest aspartate aminotransferase activity at $60^{\circ} \mathrm{C}$. Semen samples pre-incubated at various temperatures for 10 and 20 min respectively, tolerated $60^{\circ} \mathrm{C}$ without any loss of activity. Higher temperature resulted in partial or complete inactivation of the enzyme (Table 2). There was no 
difference between native seminal plasma samples and those partially purified on Sephadex G-100.

\section{Isoenzymes}

Starch gel electrophoresis and subsequent incubation of the gel at $37^{\circ} \mathrm{C}$ for localization of aspartate aminotransferase activity in the seminal plasma only revealed one strong band on the anionic side. On the other hand, extract of the spermatozoa gave one strong band on the cationic side and a weak band on the anionic side. The latter had the same position as that in the seminal plasma.

\section{Addition of pyridoxal phosphate}

The addition of 50 to $200 \mu \mathrm{g}$ pyridoxal phosphate $/ \mathrm{ml}$ gave an increase of the aspartate aminotransferase activity in all samples $(n=50)$ assayed with the colorimetric or spectrophotometric methods. There was a negative correlation between the activity in the native semen and the percentage increase after addition of pyridoxal phosphate as shown in Table 3 .

\section{DISCUSSION}

The results presented here demonstrate that the spectrophotometric method is less suitable for routine assay of aminotransferase, particularly alanine aminotransferase, in human semen, while the colorimetric method appeared acceptable for assay of aminotransferase activity in native seminal plasma provided corrections were made for the high blank values. The mean values of the aspartate and alanine aminotransferase activity obtained in this investigation agree with those previously published (Povoa \& Villela, 1960; Gregoire et al., 1961; Povoa, 1962; Searcy et al., 1962; Pumpianski \& Sharon, 1965; Joel \& Herzberg, 1965).

Optimal catalytic activity of aspartate aminotransferase was observed at $60^{\circ} \mathrm{C}$ and there was no significant inactivation of the enzyme at this temperature. These results are in agreement with those reported for aspartate aminotransferase from pig heart (Jenkins, Yphantis \& Sizer, 1959).

According to Karmen, Wróblewski \& LaDue (1955), addition of $10 \mu \mathrm{g}$ pyridoxal phosphate/ml of normal blood serum has no measurable effect on the aminotransferase activity but the effect of higher concentrations was not investigated. In the present study the addition of 20 to $200 \mu \mathrm{g}$ pyridoxal phosphate $/ \mathrm{ml}$ seminal plasma gave an increase in the aspartate aminotransferase activity of all the samples. The increase had a positive correlation to the dose and a negative correlation to the initial activity of the sample. It is known that deficiency of vitamin $B_{6}$ is associated with lower levels of aminotransferase activity in various organs and that addition of pyridoxal phosphate to the tissue samples can partially restore the enzyme activity (Lichstein, Gunsalus \& Umbreit, 1945; Schlenk \& Snell, 1945; Ames, Sarma \& Elvehjem, 1947). Cheney, Curry \& Beaton (1965) found that vitamin $B_{6}$ deficiency caused a specific reduction of aspartate aminotransferase and alanine aminotransferase activity in rat blood serum. 
Using gel electrophoresis, Decker \& Rau (1963) demonstrated three anionic and one or more cationic isoenzymes of aspartate aminotransferase in rat liver, heart and muscle extracts. In the present study, only one band (anionic) was detected in the seminal plasma. On the other hand, human spermatozoa contained mainly an aspartate aminotransferase isoenzyme with cationic properties and only a trace of the anionic form. This may indicate that the observed correlation between aspartate aminotransferase activity and sperm density in human semen (Povoa \& Villela, 1960; Povoa, 1964; Joel \& Herzberg, 1965) may not entirely be due to a leakage of the enzyme from the spermatozoa. This indication is further supported by the observation that no change in transaminase activity occurred in whole semen or seminal plasma with time. Moreover, the activity in seminal plasma was slightly lower than that of whole semen from the same individual.

\section{ACKNOWLEDGMENTS}

This investigation was supported by grants from the Swedish Medical Research Council (Projects Nos. Y 38 and Y 616) and the Population Council (Projects Nos. M-64.72 and M-65.63). The author also thankfully acknowledges the technical assistance of Mrs Barbro Luttropp and Miss Brittmarie Magnuson.

\section{REFERENCES}

Ames, S. R., Sarma, P. S. \& Elvehjem, C. A. (1947) Transaminase and pyridoxine deficiency. F. biol. Chem. 167, 135.

Cheney, M. C., Curry, D. M. \& Beaton, G. H. (1965) Blood transaminase activities in vitamin B $_{6}$ deficiency: specificity and sensitivity. Can. 7. Physiol. Pharmacol. 43, 579.

Decker, L. E. \& RAU, E. M. (1963) Multiple forms of glutamic-oxalacetic transaminase in tissues. Proc. Soc. exp. Biol. Med. 112, 144.

Flipse, R. J. (1960) Metabolism of bovine semen. IX. Glutamic-oxaloacetic and glutamic-pyruvic transaminase activities. 7. Dairy Sci. 43, 773.

Flodin, P. (1962) Dextran gels and their applications in gel filtration. Meijels Bokindustri, Halmstad.

GREGoIRE, A. T., RAKOFF, A. E. \& WARD, K. (1961) Glutamic-oxaloacetic transaminase in semen of human, bull, and rabbit seminal plasma. Int. F. Fert. 6, 73.

Jenkins, W. T., Yphantis, D. A. \& Sizer, I. W. (1959) Glutamic aspartic transaminase. F. biol. Chem. 234, 51 .

Joel, C. A. \& Herzberg, M. (1965) Glutamic-oxaloacetic transaminase in human semen and reproductive organs. F. Reprod. Fert. 10, 185.

KARMEN, A. (1955) A note on the spectrophotometric assay of glutamic-oxaloacetic transaminase in human blood serum. F. clin. Invest. 34, 131.

Karmen, A., Wróblewski, F. \& LaDue, J. S. (1955) Transaminase activity in human blood. f. clin. Invest. 34, 126.

Lichstein, H. G., Gunsalus, I. C. \& Umbreit, W. W. (1945) Function of the vitamin B $_{6}$ group: pyridoxal phosphate (codecarboxylase) in transamination. F. biol. Chem. 161, 311.

Ordell, R. (1956) Glutaminsyra-oxalättiksyra-transaminas i serum (GOTs). Opusc. med. (Stockh.), $1,14$.

PovoA, H., JR (1962) Enzyme localization in proteins separated by paper electrophoresis in human seminal plasma. Experientia, 15, 552.

PovoA, H., JR (1964) Transaminases in human semen. Invest. Urol. 2, 1.

PovoA, H., JR \& Villela, G. G. (1960) Transaminase in seminal plasma of man. Experientia, 16, 199.

Pumpianski, R. \& Sharon, A. (1965) Transaminase activity of human semen: correlation with sperm concentration. Int. F. Fert. 10, 253.

Rertman, S. \& Frankel, S. (1957) A colorimetric method for the determination of serum glutamic pyruvic transaminases. Am. F. clin. Path. 28, 56.

Schlenk, F. \& SNELl, E. E. (1945) Vitamin $B_{6}$ and transamination. F. biol. Chem. 157, 425.

Searcy, R. L., Graig, R. G. \& Bergquist, L. M. (1962) Levels of transaminases in human seminal plasma. Lancet, $\mathrm{i}, 1413$. 